Research article

\title{
Subjective response to antipsychotic treatment and compliance in schizophrenia. A naturalistic study comparing olanzapine, risperidone and haloperidol (EFESO Study) Ignacio García-Cabeza1, Juan-Carlos Gómez*2, Jose A Sacristán², Eric Edgell ${ }^{3}$ and Manuel González de Chavez ${ }^{1}$
}

\author{
Address: ${ }^{1}$ Hospital Universitario Gregorio Marañón, Madrid, Spain, ${ }^{2}$ Eli Lilly \& Company, Madrid, Spain and ${ }^{3}$ Eli Lilly \& Company, Indianapolis, \\ Indiana \\ E-mail: Ignacio García-Cabeza - igarcio@gio.ingor.upm.es; Juan-Carlos Gómez* - gomez_juan-carlos@lilly.com; \\ Jose A Sacristán - sacristan_jose@lilly.com; Eric Edgell - edgell_eric@lilly.com; Manuel González de Chavez - MGCHAVEZ@teleline.es \\ *Corresponding author
}

Published: 28 December 2001

BMC Psychiatry 200I, 1:7
Received: 26 September 2001

Accepted: 28 December 2001

This article is available from: http://www.biomedcentral.com/I47I-244X/I/7

(C) 200 I García-Cabeza et al; licensee BioMed Central Ltd. Verbatim copying and redistribution of this article are permitted in any medium for any noncommercial purpose, provided this notice is preserved along with the article's original URL. For commercial use, contact info@biomedcentral.com

\begin{abstract}
Background: In order to compare the effectiveness of different antipsychotic drugs in the treatment of schizophrenia it is very important to evaluate subjective response and compliance in patient cohorts treated according to routine clinical practice.

Method: Outpatients with schizophrenia entered this prospective, naturalistic study when they received a new prescription for an antipsychotic drug. Treatment assignment was based on purely clinical criteria, as the study did not include any experimental intervention. Patients treated with olanzapine, risperidone or haloperidol were included in the analysis. Subjective response was measured using the 10-item version of the Drug Attitude Inventory (DAl-10), and treatment compliance was measured using a physician-rated 4 point categorical scale.
\end{abstract}

Results: A total of 2128 patients initiated treatment (as monotherapy) with olanzapine, 417 with risperidone, and II 2 with haloperidol. Olanzapine-treated patients had significantly higher DAI-I0 scores and significantly better treatment compliance compared to both risperidone- and haloperidol-treated patients. Risperidone-treated patients had a significantly higher DAI-I0 score compared to haloperidol-treated patients.

Conclusion: Subjective response and compliance were superior in olanzapine-treated patients, compared to patients treated with risperidone and haloperidol, in routine clinical practice. Differences in subjective response were explained largely, but not completely, by differences in incidence of EPS.

\section{Background}

Some patients with schizophrenia report experiencing subjective sensations of change after only a few doses of neuroleptic drugs. They often complain vaguely of not feeling like themselves or somehow being limited in terms of activity. It is not uncommon to hear expressions like 'apathetic', 'mummified', ... [1] or to hear patients re- 
port that they are 'incapable of thinking straight' or feel 'like zombies' [2].

These complaints have been related to antipsycotic therapy, although not always specifically. The phenomenon has received various names including pharmacogenic depression [3], behavioural toxicity [4], subjective dysphoric response [5,1], psychophysiological sensitivity $[6,7]$, neuroleptic dysphoria' [8], neuroleptic anhedonia [9], and neuroleptic depression [10].

We have chosen the term 'subjective response' coined by Hogan et al [2]. Our feeling is that this term best reflects the individual sensation experienced by patients in response to antipsychotic treatment. According to Awad [11], this subjective response is the subjective interpretation of physiological changes following the administration of medication.

Difficulty arises when one attempts to establish the mechanism behind the nature (positive or negative) and degree of patient subjective response to medication. There does not seem to be significant sociodemographic differences between those patients with a good subjective response and those with a poor response $[12,13]$. Some authors feel that patient complaints may reflect extrapyramidal or autonomic symptoms, particularly syndromes of akinesia [14] or akathisia $[15,7,16,17]$. Further, a relationship has been inferred between subjective response and patient attitudes towards health [18] or illness $[19,20]$ or with the presence of mood changes, mainly depression and organic depression $[21,22]$. There have also been attempts to relate the mesolimbic antidopaminergic action of neuroleptic drugs to subjective response. Some authors have maintained that subjective response is more likely to be positive with atypical neuroleptics $[23,24]$.

While opinions vary regarding the mechanism behind differing subjective responses to treatment, there is unanimity when it comes to highlighting its clinical importance. Although the impact of subjective response on treatment compliance has been emphasised $[13,25,26]$, subjective response has also been identified as a prognostic and linked to treatment response, quality of life, drug abuse, and suicidality $[26-28,17,29]$.

Given its clinical significance and impact on the global outcome of treatment, it is obvious that attempts to determine the utility of new antipsychotics should include measurement of subjective response. Unfortunately, measuring subjective response is not an easy task. It is difficult to obtain externally valid results from clinical trials. Schizophrenia treatment in the context of a clinical trial is often substantially different from daily clinical practice. Clinical trials usually exclude patients with a limited awareness of their illness. In addition, schizophrenic patients who are substance abusers or who suffer with concomitant organic or psychiatric disorders, highly prevalent conditions in the schizophrenic population [30], are often excluded from clinical trials. Also, other factors such as limitations on concomitant treatments and greater control of compliance contribute to limit the generalizability of clinical trial results.

Naturalistic studies, on the other hand, provide a unique opportunity to understand the nature of subjective responses to antipsychotic treatment that patients with schizophrenia experience in the course of real-world treatment. Subjective response to antipsychotic therapy was assessed in the context of the largest prospective, naturalistic, observational study of schizophrenia conducted to date (the EFESO study). The main objective of this analysis was to compare subjective response in patients with schizophrenia treated with olanzapine with patients treated with other antipsychotics.

\section{Method}

EFESO was a prospective, comparative, observational, naturalistic study conducted in Spain designed to assess the safety of olanzapine when compared with other antipsychotic drugs in the treatment of outpatients with schizophrenia. The design and primary results of the study have been described elsewhere [31]. Data were collected on a total of 2967 patients, treated by 293 psychiatrists. Patients were eligible for the study if they were diagnosed with schizophrenia (F.20 of the ICD10). The only patients excluded were those in whom antipsychotic drug therapy was contraindicated, those in whom clozapine therapy was indicated (restricted in Spain to patients with resistant schizophrenia), and those participating in clinical trials.

Patients meeting entry criteria were enrolled upon receiving a new prescription of olanzapine or any other antipsychotic drug and agreeing to participate in the study. Physician treatment choice was by means of purely clinical criteria, with no restrictions on the clinical handling of patients and patients were not subject to experimental intervention. To limit selection bias, investigators were instructed to include all patients who received a new prescription of olanzapine or any other antipsychotic drug, who met inclusion/exclusion criteria, and who agreed to participate in the study until completing a block of 6 patients treated with olanzapine and 3 patients treated with other antipsychotics. Once a block was completed, investigators could include additional blocks until completion of the total sample. Selection of treatment was the investigators choice; therefore bias in treatment assignment could not be controlled. 
Data were collected over three visits: baseline (before receipt of their new antipsychotic prescription), after 3 months, and after 6 months of treatment. Patients discontinued the study when the principal antipsychotic prescribed at baseline was discontinued due to adverse events, lack of efficacy, or any other reason.

Secondary objectives of the study were to assess subjective response and compliance with antipsychotic treatment. Subjective response was measured using the 10 item version of the Drug Attitude Inventory (DAI) [2]. The DAI is a self-report scale developed to measure subjective responses and attitudes of chronic schizophrenic patients towards maintenance antipsychotic treatment. The original version of the scale consists of 30 items covering seven categories: subjective positive, subjective negative, health and illness, physician control, prevention, and harm. A shorter version consisting of 10 key items was subsequently developed (the DAI-10). These items are presented as self-report statements with which the patient agrees or disagrees. Each response is scored as +1 if correct or -1 if incorrect. The final score is the grand total of the positive and negative points. A positive total score means a positive subjective response. A negative total score means a negative subjective response. The DAI-10 is concise, easy to administer, and its psychometric properties are well established. The scale has been shown to have test-retest reliability, high internal consistency, and discriminant, predictive, and concurrent validity [13].

Compliance with principal antipsychotic treatment was evaluated subjectively by the treating psychiatrist according to the following scale: high (compliance with $80 \%$ of doses), moderate (compliance with $60-79 \%$ of doses), low (compliance with 20-59\% of doses) and nil (compliance with $<20 \%$ of doses). Safety was evaluated through the collection of spontaneous adverse events, and a specific questionnaire for extrapyramidal symptoms (EPS) derived from the UKU scale [32], measuring dystonia, akathisia, parkinsonism, dyskinesia, and other EPS. Global clinical status was measured through the Clinical Global Impression of Severity (CGI-S) and the Global Assessment of Functioning (GAF) scales.

\section{Statistical analyses}

Analyses were conducted in accordance with the intent to treat principle, such that data on all patients for whom information was available were included. Subjective response and compliance were compared across treatment groups that included at least 100 patients. Treatment group comparisons were conducted among patients treated with olanzapine $(\mathrm{n}=2,128)$, risperidone $(\mathrm{n}=417)$, and haloperidol $(\mathrm{n}=112)$.
The primary hypotheses tested in this analysis was that patients treated with olanzapine would experience a better subjective response to treatment and would be more compliant compared to patients treated with risperidone or haloperidol. A secondary hypothesis was that differences in subjective response would not be solely driven by differences in the incidence of extrapyramidal symptoms across treatment groups. To test this hypothesis, we compared subjective response across treatment groups after dividing the overall sample into two categories: patients who exhibited treatment emergent EPS and those who did not.

Analyses were conducted by visit, using an observed case approach, and included patients treated with olanzapine, risperidone or haloperidol who had a DAI-10 rating at baseline, after three months of treatment, and after 6 months of treatment. The Wilcoxon test, the Chi square test, and the Armitage test were used to compare mean DAI-10 scores, the proportion of patients with a positive subjective response, and the proportion of patients at different levels of compliance across treatment groups, respectively.

Phoenix International carried out the statistical analyses. The SAS ${ }^{\circledR}$ system, version 6.12 for Windows, was used for verification, validation, and analyses of the data. All analyses were post-hoc, and main effects were tested at a twosided a level of 0.05 .

\section{Results}

Table 1 shows the baseline characteristics for the three treatment groups compared in this analysis. The overall average age was approximately 35 years and approximately $36 \%$ of the patients were female. There were no statistically significant differences in the mean ages or the gender distributions between the three groups. The majority of patients (around 65\%) had a diagnosis of paranoid schizophrenia and the average time of disease duration was about 10 years. There were no statistically significant differences in the proportions of schizophrenia subtypes or the mean disease duration between the three groups. With respect to baseline severity of illness, the overall average Clinical Global Impression (CGI-S) score was between 4 (moderately ill) and 5 (markedly ill), with small (though statistically significant) differences between the groups. Olanzapine-treated patients presented with a slightly higher (more severe) mean CGI-S score than patients treated with risperidone $(\mathrm{p}<0.005)$ and with a lower mean (less severe) CGI-S score than patients treated with haloperidol $(\mathrm{p}<0.05)$. The mean initial GAF score for olanzapine-treated patients was also slightly lower (more severe) than for patients treated with risperidone ( $\mathrm{p}<$ 0.05 ) and higher (less severe) than for patients treated with haloperidol $(\mathrm{p}<0.005)$. 
Table I: Baseline characteristics of the three treatment groups.

\begin{tabular}{|c|c|c|c|c|}
\hline & $\begin{array}{c}\text { Olanzapine } \\
N=2128\end{array}$ & $\begin{array}{c}\text { Risperidone } \\
N=417\end{array}$ & $\begin{array}{c}\text { Haloperidol } \\
N=112\end{array}$ & p-value \\
\hline Age (years) & $35.6 \pm 11.7$ & $34.4 \pm 11.2$ & $34.3 \pm 10.4$ & NS \\
\hline Sex (\% females) & 36.3 & 34.1 & 39.3 & NS \\
\hline Disease Duration (years) & $11.1 \pm 9.6$ & $10.3 \pm 9.0$ & $9.5 \pm 9.5$ & NS \\
\hline \multicolumn{5}{|l|}{$\begin{array}{l}\text { Schizophrenia subtype } \\
\text { (\%) }\end{array}$} \\
\hline - Paranoid & 64.7 & 65.1 & 72.3 & \\
\hline - Undifferentiated & 13.6 & 13.7 & 11.6 & \\
\hline - Residual & 12.8 & 11.8 & 5.4 & NS \\
\hline - Disorganized & 8.4 & 8.4 & 10.7 & \\
\hline - Catatonic & 0.5 & 1.0 & 0.0 & \\
\hline Baseline CGI-S & $4.66 \pm 0.9^{1,2}$ & $4.53 \pm 0.9$ & $4.9 \pm 0.91$ & $\begin{array}{c}1 \mathrm{p}<0.005 \text { (RIS) } \\
2 \mathrm{p}<0.050 \text { (HAL) }\end{array}$ \\
\hline Baseline GAF & $44.9 \pm 14.8^{3,4}$ & $46.7 \pm 14.6$ & $40.7 \pm 16.2$ & $\begin{array}{l}3 p<0.050 \text { (RIS) } \\
{ }^{3} p<0.005 \text { (HAL) }\end{array}$ \\
\hline
\end{tabular}

Table 2: DAI- 10 score by treatment group.

\begin{tabular}{|c|c|c|c|c|}
\hline & & OLZ & RIS & HAL \\
\hline \multirow[t]{4}{*}{ Baseline } & Mean & 0,17 & 0,32 & $-1,25^{*}$ \\
\hline & SD & 5,38 & 5,24 & 5,26 \\
\hline & Median & 0 & 0 & 0 \\
\hline & $\mathrm{N}$ of observations & 2028 & 394 & 102 \\
\hline \multirow[t]{4}{*}{3 months } & Mean & 3,64 & $2,87^{* *}$ & $|, 3|+$ \\
\hline & SD & 4,66 & 4,87 & 4,98 \\
\hline & Median & 4 & 4 & 2 \\
\hline & $\mathrm{N}$ of observations & 1925 & 375 & 101 \\
\hline \multirow[t]{4}{*}{6 months } & Mean & 4,63 & $3,42++$ & $1,68+$ \\
\hline & SD & 4,34 & 4,97 & 5,2 \\
\hline & Median & 6 & 4 & 2 \\
\hline & $\mathrm{N}$ of observations & 1740 & 354 & 95 \\
\hline
\end{tabular}

${ }^{*} \mathrm{p}<0,05$ vs. OLZ and RIS; ${ }^{*} \mathrm{p}=0,003$ vs OLZ; $+\mathrm{p}<0,001$ vs OLZ and $\mathrm{p}=0,003$ vs RIS; $++\mathrm{p}<0,001$ vs OLZ

The initial mean dose of olanzapine was $12.2 \mathrm{mg} /$ day and the overall mean dose was $13 \mathrm{mg} /$ day. In the case of risperidone, the initial and the overall mean doses were 5.2 and $5.4 \mathrm{mg} /$ day, respectively. The initial and overall mean doses of haloperidol were 13.9 and $13.6 \mathrm{mg} / \mathrm{day}$, respectively. The median doses (both initially and overall) were $10 \mathrm{mg} /$ day for olanzapine, $6 \mathrm{mg} /$ day for risperidone, and $10 \mathrm{mg} /$ day for haloperidol.

Subjective response by treatment group as measured using the DAI-10 is summarised in Table 2. All three treatment groups had a positive subjective response to treatment.
Olanzapine-treated patients had a significantly better subjective response at both the three and six month time points compared to both risperidone- and haloperidoltreated patients. Risperidone-treated patients had a significantly better subjective response to treatment at both the three $(\mathrm{p}=0.003)$ and $\operatorname{six}(\mathrm{p}=0.003)$ month time points compared to haloperidol-treated patients.

The vast majority of patients had a positive subjective response to treatment at both the three and six month time points regardless of treatment group (see Table 3 ). A significantly larger percentage of olanzapine-treated patients 
Table 3: Number and percentage of patients with a positive score in the DAl- 10 by treatment group

\begin{tabular}{|c|c|c|c|c|}
\hline & & $\begin{array}{c}\text { OLZ } \\
N=2128\end{array}$ & $\begin{array}{c}\text { RIS } \\
N=4 I 7\end{array}$ & $\begin{array}{c}\text { HAL } \\
N=112\end{array}$ \\
\hline \multirow[t]{2}{*}{ Baseline } & $N$ & 960 & 196 & 36 \\
\hline & $\%$ & 53,1 & 56,6 & $42,4^{*}$ \\
\hline \multirow[t]{2}{*}{3 months } & $\mathrm{N}$ & 1458 & 259 & 58 \\
\hline & $\%$ & $82,3^{\text {** }}$ & 76,4 & 68,2 \\
\hline \multirow[t]{2}{*}{6 months } & $\mathrm{N}$ & 1423 & 252 & 55 \\
\hline & $\%$ & $88,1+$ & $78++$ & 67,9 \\
\hline
\end{tabular}

${ }^{*} \mathrm{p}=0,01$ vs RIS; ${ }^{*} \mathrm{p} \leq 0,01 \mathrm{I}$ vs RIS and HAL; $+p=0,001$ vs RIS and HAL; $++p=0,05$ vs HAL

Table 4: Compliance with principal antipsychotic treatment by treatment group. Percentage of patients at each compliance level.

\begin{tabular}{|c|c|c|c|c|c|}
\hline & & OLZ & RIS & HAL & $\mathrm{p}$-value \\
\hline \multirow[t]{4}{*}{3 months } & High & 83,3 & 77,7 & 76,5 & NS \\
\hline & Moderate & 11,2 & 18,1 & 17,6 & \\
\hline & Low & 3,8 & 3,6 & 4,9 & \\
\hline & $\mathrm{Nil}$ & 1,7 & 0,5 & 1 & \\
\hline \multirow[t]{4}{*}{6 months } & High & 84,8 & 74,2 & 69,8 & OLZ vs RIS, $p=0,001$ \\
\hline & Moderate & $\mathrm{II}, \mathrm{I}$ & 19,4 & 27,1 & OLZ vs HAL, $P=0,022$ \\
\hline & Low & 2,5 & 5 & 2,1 & \\
\hline & Nil & 1,6 & $\mathrm{I}, 4$ & 1 & \\
\hline
\end{tabular}

had a positive subjective response at both the three and six month time points compared to risperidone- and haloperidol-treated patients. A significantly larger proportion of risperidone-treated patients had a positive subjective response at six months compared to haloperidol-treated patients.

Treatment group rates of compliance as assessed by physician rating are detailed in Table 4 . Olanzapine-treated patients were rated as significantly more compliant than both risperidone- $(\mathrm{p}=0.001)$ and haloperidol-treated ( $\mathrm{p}$ $=0.022$ ) patients at six months.

Differences between olanzapine, risperidone and haloperidol in subjective response by EPS category (presence or absence of treatment emergent EPS) are shown in Table 5. DAI-10 scores were higher across all three treatment groups for those patients who did not experience treatment-emergent EPS. Olanzapine-treated patients had a significantly better subjective response at six month time points compared to risperidone-treated patients regardless of EPS category. Olanzapine-treated patients had a significantly better subjective response than haloperidoltreated patients in the treatment-emergent EPS subgroup.
There were no significant differences between olanzapine and haloperidol with respect to subjective response in the subgroup without EPS. Risperidone-treated patients had a significantly better $(\mathrm{p}=0.0015)$ subjective response rating compared to haloperidol-treated patients in the subgroup of patients with EPS but not in the subgroup without EPS at month 6 .

\section{Discussion}

The EFESO study is the first large prospective observational study conducted with atypical antipsychotics, including a control group, of which we are aware. Previous published results from the EFESO study have shown that olanzapine-treated patients have achieved superior outcomes compared to patients treated with risperidone or haloperidol $[31,33,34]$. Statistically significant findings favouring olanzapine-treated patients compared to risperidone- and/or haloperidol-treated patients have included the proportion of patients who experienced at least one adverse event, the percentage of patients who developed EPS, and the proportion of responders at month six (olanzapine compared to risperidone). Risperidone is known to induce EPS in a dose-dependent fashion and therefore, results might have been different if risperidone had been 
Table 5: DAI- 10 score by treatment group and by presence/absence of EPS.

\begin{tabular}{|c|c|c|c|c|c|}
\hline $\begin{array}{l}\text { Patients with } \\
\text { EPS }\end{array}$ & & $\begin{array}{c}\text { OLZ } \\
N=688\end{array}$ & $\begin{array}{c}\text { RIS } \\
N=189\end{array}$ & $\begin{array}{c}\text { HAL } \\
\mathrm{N}=79\end{array}$ & p-value \\
\hline \multirow[t]{5}{*}{ Baseline } & Mean & 0,45 & $-0,36$ & $-|, 3|$ & $\begin{array}{l}\text { OLZ vs RIS, NS; OLZ } \\
\text { vs HAL, }\end{array}$ \\
\hline & & & & & $\begin{array}{l}\mathrm{P}<0,05 ; \text { RIS vs HAL, } \\
\text { NS }\end{array}$ \\
\hline & SD & 5,12 & 5,27 & 5,16 & \\
\hline & Median & 0 & 0 & 0 & \\
\hline & $\mathrm{n}$ of observations & 667 & 184 & 72 & \\
\hline \multirow[t]{5}{*}{6 months } & Mean & 4,13 & 2,95 & 0,87 & $\begin{array}{l}\text { OLZ vs RIS, P = } \\
0,003 \mathrm{I} ; \text { OLZ vs HAL, }\end{array}$ \\
\hline & & & & & $\begin{array}{l}\mathrm{P}<0,00 \mathrm{I} ; \mathrm{RIS} \text { vs HAL, } \\
\mathrm{P}=0,0015\end{array}$ \\
\hline & SD & 437 & 4,75 & 4,8 & \\
\hline & Median & 6 & 4 & 2 & \\
\hline & $\mathrm{n}$ of observations & 594 & 170 & 69 & \\
\hline Patients & & OLZ & RIS & HAL & p-value \\
\hline without EPS & & $N=1175$ & $N=192$ & $N=25$ & \\
\hline \multirow[t]{4}{*}{ Baseline } & Mean & $-0,02$ & 0,82 & $-0,17$ & $\begin{array}{l}\text { OLZ vs RIS, NS; OLZ } \\
\text { vs HAL, NS; RIS vs } \\
\text { HAL, NS }\end{array}$ \\
\hline & SD & 5,51 & 5,19 & 5,72 & \\
\hline & Median & 0 & 2 & 0 & \\
\hline & $\mathrm{n}$ of observations & 1118 & 178 & 24 & \\
\hline \multirow[t]{4}{*}{6 months } & Mean & 4,9 & 3,85 & 4,42 & $\begin{array}{l}\text { OLZ vs RIS, } p=0,033 ; \\
\text { OLZ vs HAL, NS; RIS } \\
\text { vs HAL, NS }\end{array}$ \\
\hline & SD & 43 & 5,15 & 534 & \\
\hline & Median & 6 & 6 & 6 & \\
\hline & $\mathrm{n}$ of observations & 1128 & 183 & 24 & \\
\hline
\end{tabular}

lower. Nevertheless, risperidone dose in this study is consistent with published reports from clinical practice [39].

The findings of the present analysis build on these previous findings. In this analysis, olanzapine was found to be superior to both risperidone and haloperidol in terms of subjective response and compliance. Further, subjective response was significantly better in patients treated with risperidone compared to patients treated with haloperidol. The global incidence rate of adverse events and extrapyramidal symptoms followed a similar pattern across treatment groups, being greater for haloperidol and lowest for olanzapine, with risperidone somewhere in the middle [31]. This raises the issue of the potential relationship between adverse events, particularly EPS, and patient's subjective response to antipsychotic treatment. This fact would be in line with the opinion of some authors regarding the possibility that neuroleptic dysphoria is an affective component in extrapyramidal effects or an element in akathisia $[16,17]$. Thus, atypical drugs with a more favourable EPS profile, are thought to be associated with a better subjective response than haloperidol or other con- ventional drugs, perhaps not so much through the direct mechanism of action but rather through the generation of a lower rate of extrapyramidal effects.

It would seem reasonable to postulate that patients who perceive the benefits of medication through the relief of their symptoms and fewer unpleasant adverse events will tend to have a more positive attitude, whereas those who present highly incapacitating adverse events will not. The DAI-10 was, to a large extent, designed to detect subjective impact of EPS. Nevertheless, the results of our secondary analyses suggest that EPS do not provide a full explanation of the differences in subjective response between treatments. DAI-10 scores were significantly higher in the groups without EPS, regardless of antipsychotic treatment, suggesting that EPS are a major contributor to negative subjective responses. However, there were significant differences between olanzapine- and risperidone-treated patients in terms of subjective response regardless of whether patients exhibited EPS. This may indicate that differences in EPS are not the sole explanation for differences in subjective response. In the comparison between pa- 
tients treated with olanzapine or risperidone versus haloperidol, there were significant differences only in the subgroup of patients who experienced EPS. The small sample size of the subgroup of patients treated with haloperidol and without EPS $(\mathrm{N}=25)$ should be taken into account in the interpretation of these data.

It is interesting to note that olanzapine treated patients were rated as more compliant with treatment compared to risperidone and haloperidol-treated patients. This finding suggests a potential relationship between subjective response and treatment compliance. Using different measurement scales, other studies $[1,35,2,25,26,19]$ have highlighted the importance of subjective response in a subject's decision to take antipsychotic medication. It seems logical that how a patient feels and operates is going to influence future compliance [20]. Nevertheless, it is important to take into account that compliance was measured in an exploratory fashion, using a scale that could benefit from additional development and validation. Therefore, definitive conclusions should not be drawn from these results.

One should note that a larger proportion of olanzapinetreated patients exhibited a positive subjective response and clinical response to treatment [31] compared to both risperidone- and haloperidol-treated patients. Differences in clinical response may be linked to differences in subjective response. Singh, Smith and Kay [36,37] demonstrated that poor clinical response was associated with a dysphoric subjective response following administration of medication. Other studies have since confirmed these initial findings $[1,35]$, and subjective response has been identified as an indicator of initial response to antipsychotics $[38,13]$. One should note, however, that these previous studies have been focused on early (during the initial days of treatment) subjective response, while we measured response at 3 and 6 months of treatment. There is a recent publication of a cross-sectional study that reports better subjective response measured with the DAI-30 in patients treated with new antipsychotics compared to conventional antipsychotics, but not difference between different new antipsychotics (risperidone, olanzapine, quetiapine and clozapine) [40].

When considering the results of the present analysis one should consider the following methodologic limitations associated with naturalistic studies: [1] selection bias secondary to lack of randomisation; [2] additional problems in establishing unequivocal causal relationship due to frequent use of concomitant medication; [3] difficulty in keeping a strict control of the study because of the number of participants, as shown by the majority of drop-outs being due to unknown reasons; and [4] unbalanced sample size by treatment groups. Despite these limitations we feel that our findings merit consideration when one is making antipsychotic treatment choices, because the study closely mimics the real-world clinical conditions Additional File.

\section{Conclusions}

This naturalistic study shows that subjective response and compliance were better in patients treated with olanzapine, compared to patients treated with risperidone and haloperidol, in routine clinical practice. Subjective response was also significantly better in patients treated with risperidone compared to patients treated with haloperidol. Differences in subjective response were explained largely, but not completely, by differences in incidence of EPS.

\section{Competing interests}

Gómez JC, Sacristán JA and Edgell E are employees of Eli Lilly and Company, manufacturer of Zyprexa ${ }^{\mathrm{TM}}$ (olanzapine).

\section{Additional material}

\section{Additional file}

Participants of the EFESO study

Click here for file

[http://www.biomedcentral.com/content/supplementary/1471-

244x-1-7-s1.doc]

\section{Acknowledgements}

Thanks are due to Raul Vara and to Fernando Gonzalo, Biometrics Department, Phoenix International Spain. We would like to thank the participants of the EFESO study.

\section{References}

I. Van Putten T, May PRA: Subjective response as a predictor of outcome in pharmacotherapy: the consumer has a point. Arch Gen Psychiatry 1978, 35:477-480

2. Hogan TP, Awad AG, Eastwood R: A self-report scale predictive of drug compliance in schizophrenics: reliability and discriminative validity. Psychol Med 1983, I 3:177-183

3. Helmchen $\mathrm{H}$, Hippius $\mathrm{H}$ : Pharmakogen depression. In: Das depressive syndrom (Edited by Hippius H) Munich, Schattauer 1969443-448

4. Dimascio A: Behavioural toxicity. In: Clinical Handbook of Psychopharmacology (Edited by DiMascio A, Y Shader RI) Nueva York, Science House 1970185-193

5. Singh MM: Dysphoric response to neuroleptic treatment in schizophrenia and its prognostic significance. Dis Nerv Syst 1976, 37:191-196

6. Lipowsky ZJ: The importance of body experience for psychiatry. Compr Psychiatry 1977, 18:473-479

7. Hogarty GC, Schooler NR, Ulrich R, Mussare F, Peregrino F, Herron $\mathrm{H}$ : Fluphenazine and social therapy in the aftercare of schizophrenics patients. Relapse analyses of a two-year controlled study of fluphenazine decanoate and fluphenazine hydrochloride. Arch Gen Psychiatry 1979, 36:1283-1294

8. Emerich DF, Sanberg PR: Neuroleptic dysphoria. Biol Psychiatry I991, 29:201-203

9. Wise RA: Neuroleptic-induced anhedonia. Recent studies. In: Advances in Neuropsychiatry and Psychopharmacology: Schizophrenia Research (Edited by Taminga CA) New York, Raven Press I99I323-33 I

10. Harrow M, Fichtner CG, Grossman LS: Neuroleptic depression in chizophrenia. Biol Psychiatry 1991, 30:844-848 
II. Awad AG: Subjective response to neuroleptics in schizophrenia. Schizophr Bull 1993, 19:609-618

12. Awad AG, Hogan TP: Drug therapy in schizophrenia: prediction of outcome. Schizophr Res 1988, I:222

13. Hogan TP, Awad AG: Subjective response to neuroleptics and outcome in schizophrenia: a re-examination comparing two measures. Psychol Med 1992, 22:347-352

14. Rifkin A, Quitklin F, Klein DF: Akinesia. Arch Gen Psychiatry 1975, 32:672-674

15. Falloon I, Watt DC, Shepherd MA: A comparative controlled trial of pimozide and fluphenazine decanoate in the continuation therapy of schizophrenia. Psychol Med 1978, 8:59-70

16. Van Putten T, May PRA, Marder SR: Response to antipsychotic medication: the doctor's and consumer's view. Am J Psychiatry 1984, 141:16-19

17. Voruganti LN, Heslegrave RJ, Awad AG: Neuroleptic dysphoria may be the missing link between schizophrenia and substance abuse. I Nerv Mental Dis 1997, 185:463-465

18. Kelly G, Mamon J, Scott J: Utility of the health belief model in examining medication compliance among psychiatric outpatients. Soc Sci Med 1987, 25:I 203-12। I

19. Kemp R, David A: Psychological predictors of insight and compliance in psychotic patients. Br \ Psychiatry, 1996, 169:444-450

20. Garcia Cabeza I, Sanz Amador M, Arango Lopez C, Gonzalez de Chavez M: Subjective response to antipsychotics in schizophrenia patients: clinical implications and related factors. Schizophr Res 2000, 41:349-355

21. Caine ED, Polinsky RJ: Haloperidol induced dysphoria in patients with Tourette's syndrome. Am J Psychiatry 1979, 1 36: I2161217

22. Bruun RD: Subtle and unrecognized side effects of neuroleptic treatment in children with Tourette's disorder. Am J Psychiatry 1988, | 45:62। -624

23. Gebhard R: Veränderungen der subjektiven befindlichkeit psychotischer patienten unter neuroleptischer therapy. Pharmacopsychiatry 1972, 5:295-300

24. Naber D, Holzbach R, Perro C, Hippius $\mathrm{H}$ : Clinical management of clozapine patients in relation to efficacy and side-effects. Br J Psychiatry Suppl 1992, 160:54-59

25. Weiden P, Rapkin B, Mott T, Zygmunt A, Goldman D, Horvitz M, Frances $A$ : Rating of medication influences (ROMI) scale in schizophrenia. Schizophr Bull 1994, 20:297-310

26. Naber $D$ : A self-rating to measure subjective effects of neuroleptic drug, relationships to psychopathology, quality of life, compliance and other clinical variables. Int Clin Psychopharmacol Suppl 1995, 10:133-138

27. Awad AG, Hogan TP, Voruganti LNP, Heslegrave RJ: Patients' subjective experiencies on antipsychotic medications: implications for outcome and quality of life. Int Clin Psychopharmacol Suppl 1995, 1 0:123-132

28. Awad AG, Voruganti LN, Heslegrave RJ, Hogan TP: Assesment of the patient's subjective experience in acute neuroleptic treatment: implications for compliance and outcome. Int Clin Psychopharmacol Suppl 1996, I I:55-59

29. Browne S, Garavan J, Gervin M, Roe M, Larkin C, O'Callaghan E: Quality of Life in schizophrenia: insight and subjective response to neuroleptics. J Nerv Mental Dis 1998, 186:74-78

30. Buckley PF: Substance abuse in schizophrenia: a review. / Clin Psychiatry 1998, 59:26-30

31. Gomez JC, Sacristan JA, Hernandez J, Breier A, Ruiz-Carrasco P, Anton-Saiz C, Fontova-Carbonell E: The safety of olanzapine compared to other antipsychotic drugs: Results of an observational prospective study in patients with schizophrenia (EFESO study). I Clin Psychiatry 2000, 6 I:335-343

32. Lingjaerde O, Ahlors UG, Bech P, Dencker SJ, Elgen K: The UKU side effect rating scale. A new comprehensive rating scale for psychotropic drugs and a cross-sectional study of side effects in neuroleptic-treated patients. Acta Pychiatr Scand Suppl 1987, 334: $1-100$

33. Badia X, Casado A, Sacristan JA, Gomez JC, Gregor KJ: Antipsychotic treatment and changes in health related quality of life in patients with schizophrenia using EQ-5D. Podium Presentation. Second Annual European Meeting of the International Society for PharmacoEconomics and Outcomes Research, Edinburgh, Scotland, November, 1999
34. Sacristan JA, Gomez JC, Montejo AL, Vieta E, Gregor KJ, The EFESO Study Group: Doses of olanzapine, risperidone and haloperidol used in clinical practice: Results of a prospective pharmacoepidemiologic study. EFESO Study Group. Estudio Farmacoepidemiologico en la Esquizofrenia con Olanzapina. Clin Ther 2000, 22:583-599

35. Van Putten T, May PRA, Marder SR, Wittman LA: Subjective response to antipsychotic drugs. Arch Gen Psychiatry 198I, 38:187190

36. Singh MM, Smith JM: Kinetics and dynamics of response to haloperidol in acute schizophrenia: its relationship to autonomic arousal and prognosis: a longitudinal study of the therapeutic process. Compr Psychiatry 1973, 14:178-179

37. Singh MM, Kay SR: Dysphoric response to neuroleptic treatment in schizophrenia: Its relationship to autonomic arousal and prognosis. Biol Psychiatry 1979, 14:277-294

38. Awad AG, Hogan TP: Early treatment events and prediction of response to neuroleptics in schizophrenia. Prog Neuropsychopharmacol Biol Psychiatry 1985, 9:585-589

39. Chouinard G, Kopala L, Labelle A, For the RIS-CAN-3 Study Group, et al: Phase IV multicentre clinical study of risperidone in the treatment of outpatients with schizophrenia. Can J Psychiatry 1998, 43:1018-1025

40. Voruganti L, Cortese L, Oyewumi L, et al: Comparative evaluation of conventional and novel antipsychotic drugs, with reference to their subjective tolerability, side effect profile and impact on quality of life. Schiz Res 2000, 43: 135- I 45

\footnotetext{
Publish with BioMed Central and every scientist can read your work free of charge

"BioMedcentral will be the most significant development for disseminating the results of biomedical research in our lifetime."

Paul Nurse, Director-General, Imperial Cancer Research Fund

Publish with BMC and your research papers will be:

- available free of charge to the entire biomedical community

- peer reviewed and published immediately upon acceptance

- cited in PubMed and archived on PubMed Central

- yours - you keep the copyright

Submit your manuscript here:

http://www.biomedcentral.com/manuscript/

BioMedcentral.com editorial@biomedcentral.com
} 